\title{
A QUANTITATIVE INTERPRETATION OF DSC EXPERIMENTS ON QUENCHED AND AGED SICP REINFORCED 8090 ALLOYS
}

\author{
M.J. Starink and P.J. Gregson \\ Dept. of Engineering Materials, University of Southampton, \\ Highfield, Southampton S017 1BJ, United Kingdom
}

\author{
1 Introduction
}

Differential Scanning Calorimetry (DSC) is a useful technique for the study of phase transformations and has been widely applied to study precipitation in aluminium alloys, but the results are generally interpreted qualitatively. Quantitative interpretation of DSC experiments on binary and ternary aluminium-based alloys has been attempted (see Ref. 1,2,3), and can improve understanding of their thermodynamics and kinetics of precipitation.

In the present paper a quantitative interpretation of DSC heat effects occurring in 8090 alloys with and without SiC particle reinforcement is presented. Hardening of 8090 alloys (nominal composition $\mathrm{Al}-1.3 \mathrm{wt} \% \mathrm{Cu}-1 \mathrm{wt} \% \mathrm{Mg}-2.5 \mathrm{wt} \% \mathrm{Li}$ ) is generally interpreted in terms of two precipitation sequences $(4,5,6)$ :

where $\delta^{\prime}$ is a L12 ordered phase $\left(\mathrm{Al}_{3} \mathrm{Li}\right)$, fully coherent with the Al matrix, and $\delta$ is the equilibrium Al-Li phase (AlLi), which forms mainly at grain boundaries (7)

ii) $\quad \mathrm{Cu}, \mathrm{Mg}$ in Al-rich phase $\rightarrow$ GPB zones $\rightarrow \mathrm{S}^{\prime} \rightarrow \mathrm{S}$

where GPB zones are $\mathrm{Cu}$ and $\mathrm{Mg}$ containing Guinier-Preston zones (8), and $\mathrm{S}^{\prime}$ is a slightly strained semicoherent version of the incoherent $\mathrm{S}\left(\mathrm{Al}_{2} \mathrm{CuMg}\right)$ (see Ref. 9). Since the formation enthalpies of the two variants are the same (10), $\mathrm{S}^{\prime}$ and $\mathrm{S}$ will be considered to be the same phase in this paper.

Furthermore, the icosahedral I phase (proposed composition $\mathrm{Al}_{6} \mathrm{Cu}(\mathrm{Li}, \mathrm{Mg})_{3}$, see Ref. 11), forms on grain boundaries (12). Because of the multiple precipitates involved, interpretation of precipitation reactions in 8090 alloys is complex, and an understanding of the amounts of the different phases formed during ageing is important. This paper sets out to present a quantitative description of the precipitate microstructure in monolithic and reinforced 8090, with particular reference to GPB zones and $\delta^{\prime}$ phase precipitates.

\section{Experimental Procedures}

2.1. Sheet production The alloys were produced at Structural Materials Centre, DRA Farnborough via a powder metallurgical route and rolled at $510^{\circ} \mathrm{C}$ to a sheet thickness of about $2.3 \mathrm{~mm}$. Details of the production route are given elsewhere (10). The compositions of the matrix of the alloys are given in Table 1 . The metal matrix composite (MMC) contains $20 \mathrm{wt} \% \mathrm{SiC}$ particles with an average size of $3 \mu \mathrm{m}$.

2.2 Heat treatment Disc-shaped DSC samples (thickness $\sim 0.8 \mathrm{~mm}$ ) were machined and punched prior to heat treatments and were solution treated in air for 0.5 hour at $530^{\circ} \mathrm{C}$ using a standard convection furnace. The solution treatment and all subsequent heat treatments were terminated by a direct quench into water at room temperature. For ageing treatments the samples were transferred to an oven at $170^{\circ} \mathrm{C} \pm 1.5^{\circ} \mathrm{C}$ within 1.5 minutes of the solution treatment. Ageing times ranged between $0.17 \mathrm{~h}(10 \mathrm{~min})$ and $168 \mathrm{~h}$ (7 days). Reversion treatments consisting of a $5 \mathrm{~min}$ hold at $286^{\circ} \mathrm{C}$ were performed on samples aged for 7 days.

2.3 Differential Scanning Calorimetry DSC experiments were started 5 min after completion of the previous heat treatment. All runs are corrected for the baseline of the DSC and for the difference of the heat capacity of the sample and reference (10). More details of the experimental set-up and procedure are given elsewhere (10). 
TABLE 1: $\quad$ Compositions of the matrix alloys (in weight percent).

$\begin{array}{llllll}\text { Alloy } & \mathrm{Li} & \mathrm{Cu} & \mathrm{Mg} & \mathrm{Zr} & \mathrm{Al} \\ 8090 \text { monolithic } & 2.34 & 1.25 & 1.04 & 0.11 & \text { remainder } \\ 8090 \mathrm{MMC} & 2.40 & 1.16 & 0.75 & 0.10 & \text { remainder }\end{array}$

\section{Results}

The first runs of freshly solution treated and quenched specimens of the two alloys studied are presented in Figs. 1 and 2 . A total of 6 effects, marked A to F, are observed. The identification of these effects has been discussed previously (see Ref. 10) and is in line with most publications on DSC work in Al-Cu-Mg monolithic alloys and MMCs $(5,13,14,15)$, and Al-Cu-Mg-Li monolithic alloys and MMCs $(5,6,16)$. Effect $\mathrm{A}$ is most clearly observed in the monolithic 8090 alloy and is ascribed to GPB-zone formation; some evidence for this effect is observed for the MMC. Effect B in the MMC is ascribed to $\delta^{\prime}$ formation. For the monolithic alloy only at heating rate $2^{\circ} \mathrm{C} / \mathrm{min}$ some indications for the presence a $\delta^{\prime}$ formation effect is observed. Effect $\mathrm{C}$ is attributed to $\delta^{\prime}$ and GPB-zone dissolution. Effect $\mathrm{D}$ is ascribed mainly to $\mathrm{S}^{\prime}$ precipitation, but $\delta$ and I phase formation (both form mainly at grain boundaries, see Refs. 7,12) might additionally contribute to some degree. Effect $\mathrm{E}$ is ascribed to the dissolution of the phases formed during effect $\mathrm{D}$. The exothermic effect $\mathrm{F}$ is attributed to the formation of $\mathrm{Li}_{2} \mathrm{CO}_{3}$ or $\gamma-\mathrm{LiAlO}_{2}$ on the surface of the samples. One day ageing at room temperature prior to DSC does not affect the DSC curves.
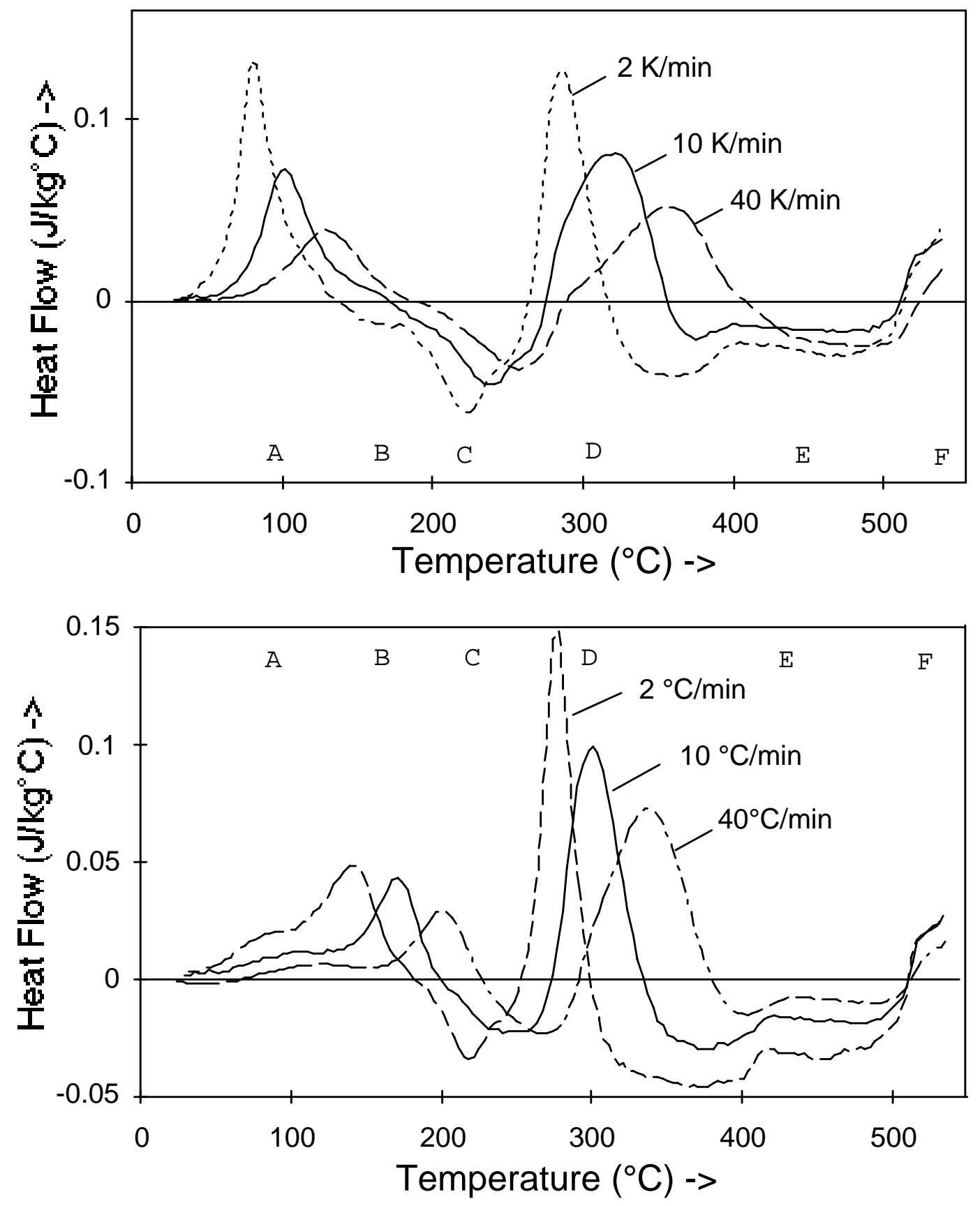

Fig. 1:

DSC curves of the solution treated and quenched monolithic 8090 alloy at varying heating rates.

Fig. 2

DSC curves of the solution treated and quenched $8090 \mathrm{MMC}$ at varying heating rates. 
As precipitation and dissolution effects are thermally activated processes the heat effects observed in Figs. 1 and 2 shift to higher temperatures with increasing heating rate. From the peak temperatures of the effects the (apparent) activation energies for the precipitation reactions can be obtained using so-called Kissinger plots $(17,18,19)$. This yields: $\mathrm{E}_{\delta^{\prime}}=74 \pm 4 \mathrm{~kJ} / \mathrm{mole}, \mathrm{E}_{\mathrm{S}^{\prime}}=$ $107 \pm 4 \mathrm{~kJ} / \mathrm{mole}$ (for the $8090 \mathrm{MMC}$ ), and $\mathrm{E}_{\mathrm{GPB}}=66 \pm 5 \mathrm{~kJ} / \mathrm{mole}, \mathrm{E}_{\mathrm{S}^{\prime}}=122 \pm 6 \mathrm{~kJ} / \mathrm{mole}$ (for monolithic 8090). The correlation coefficients of the plots were all better than 0.995 . The activation energies for GPB and $\mathrm{S}^{\prime}$ formation in the monolithic 8090 alloy agree well with those obtained by other workers for GPB and $\mathrm{S}^{\prime}$ formation in the monolithic 8090 alloy $(6,16)$ and in $\mathrm{Al}-\mathrm{Cu}-\mathrm{Mg}$ alloys (13).

\section{Discussion}

It is apparent that some overlap occurs between effect $\mathrm{D}$ and the combined $\delta^{\prime}$ and GPB-zone dissolution effect (effect C), but a method for obtaining a correction for this overlap can be developed. From classical reaction kinetics theory it follows that during heating at a constant rate the maximum reaction rate (i.e. the peak of the DSC heat effect) occurs at a fixed stage of the reaction, i.e. at a fixed fraction, $f_{p}$, of the total heat evolving during that reaction $(17,18,19)$. Providing that the peak temperature of the $S^{\prime}$ precipitation effect is not influenced by overlap, it is possible to calculate the amount of overlap using the amount of heat evolved in the part of the heat effect following the peak. It is believed that $\mathrm{f}_{\mathrm{p}}$ for the $8090 \mathrm{MMC}$ is identical to that in the solution treated $\mathrm{Al}-\mathrm{Cu}-\mathrm{Mg}-1.5 \mathrm{Li} \mathrm{MMC}$, and this can be obtained without any interference of overlap from the curve presented in Ref. 10, resulting in $\mathrm{f}_{\mathrm{p}}=0.69 \pm 0.01$. The values for $\mathrm{f}_{\mathrm{p}}$ as obtained using the curves by Jena et al. for the monolithic Al- $1.53 \mathrm{wt} \% \mathrm{Cu}-0.79 \mathrm{wt} \% \mathrm{Mg}$ increase with heating rate from about 0.44 at $5^{\circ} \mathrm{C} / \mathrm{min}$ to about 0.83 at $20^{\circ} \mathrm{C} / \mathrm{min}$. This is thought to be due to: i) extensive overlap with the GPB-zone dissolution effect at $5^{\circ} \mathrm{C} / \mathrm{min}$, which would tend to underestimate $\mathrm{f}_{\mathrm{p}}$, and ii) a strongly reduced heat effect at $20^{\circ} \mathrm{C}$, rendering the reaction kinetics theory $(18,19)$ invalid. Hence, only the intermediate heating rates $\left(10\right.$ and $\left.15^{\circ} \mathrm{C} / \mathrm{min}\right)$ at which $\mathrm{f}_{\mathrm{p}}$ is indeed approximately constant are used, resulting in $\mathrm{f}_{\mathrm{p}}=0.69$ (i.e. the same as for the $\mathrm{MMC}$ ). Using this value the overlap between effects $\mathrm{C}$ and $\mathrm{D}$ is obtained.

The combined heat content of effects $\mathrm{A}, \mathrm{B}$ and $\mathrm{C}$ in the solution treated alloys corrected for overlap, $\Delta \mathrm{Q}_{\delta^{\prime} / \mathrm{GPB}}$, are presented in Table 2. The table shows that the $\Delta \mathrm{Q}_{\delta^{\prime}} / \mathrm{GPB}$ values calculated at heating rates 10 and $40^{\circ} \mathrm{C} / \mathrm{min}$ correspond well, giving a first indication that the overlap correction, when applied for these heating rates, is sound. $\Delta \mathrm{Q}_{\delta^{\prime}} / \mathrm{GPB}$ averages $-2.2 \mathrm{~J} / \mathrm{g}$ for the 8090 monolithic alloy and $-3.2 \mathrm{~J} / \mathrm{g}$ for the $8090 \mathrm{MMC}$. The deviation at heating rate $2^{\circ} \mathrm{C} / \mathrm{min}$, which is especially large for the monolithic alloy, is thought to be due to extensive overlap with effect $\mathrm{C}$, influencing the peak temperature of effect $\mathrm{D}$. As the overlap correction is very sensitive to the determination of the peak temperature, even a small shift in the peak temperature of about $1.5^{\circ} \mathrm{C}$ can explain the observed deviation for the monolithic alloy.

TABLE 2 The uncorrected $\left(\triangle \mathrm{Q}_{\mathrm{ABC}}\right)$ and overlap-corrected $\left(\Delta \mathrm{Q}_{\delta^{\prime} / \mathrm{GPB}}\right)$ heat effects of GPB-zone and $\delta^{\prime}$-phase formation. 8090 monolit

\begin{tabular}{|c|c|c|c|c|c|c|}
\hline $\begin{array}{l}\text { Heating Rate } \\
\left({ }^{\circ} \mathrm{C} / \mathrm{min}\right)\end{array}$ & $f_{p}$ measured & $\begin{array}{c}\Delta \mathrm{QABC}_{\mathrm{ABC}} \\
(\mathrm{J} / \mathrm{g})\end{array}$ & $\begin{array}{c}\Delta \mathrm{Q}_{\delta^{\prime} / \mathrm{GPB}} \\
(\mathrm{J} / \mathrm{g})\end{array}$ & $f_{p}$ measured & $\begin{array}{c}\Delta \mathrm{Q}_{\mathrm{ABC}} \\
(\mathrm{J} / \mathrm{g})\end{array}$ & $\begin{array}{c}\Delta \mathrm{Q}_{\delta^{\prime} / \mathrm{GPB}} \\
(\mathrm{J} / \mathrm{g})\end{array}$ \\
\hline 2 & 0.47 & $3.1 \pm 1.2$ & $-6.2 \pm 2.3$ & 0.61 & 6.9 & -4.0 \\
\hline 10 & 0.62 & $1.2 \pm 0.9$ & $-2.4 \pm 1.4$ & 0.53 & 5.9 & -2.9 \\
\hline 40 & 0.62 & $0.6 \pm 0.8$ & $-2.0 \pm 1.1$ & 0.45 & 2.6 & -3.5 \\
\hline
\end{tabular}

From the negative values observed for $\Delta \mathrm{Q}_{\delta^{\prime} / \mathrm{GPB}}$ it appears that during the DSC heating a low temperature phase which was present right after quenching, dissolves. This observation is consistent with TEM and high resolution TEM work on reinforced and unreinforced 8090 alloys, which show that directly after quenching a lithium-containing L12 ordered phase is present $(5,20)$.

Using the correction for the overlap $\Delta \mathrm{Q}_{\delta^{\prime} / \mathrm{GPB}}$ and the heat effect due to $\mathrm{S}^{\prime}$ formation, $\Delta \mathrm{Q}_{\mathrm{S}^{\prime}}$, are calculated from DSC curves of aged reinforced and unreinforced 8090 obtained at heating rate $10^{\circ} \mathrm{C} / \mathrm{min}$ (see Ref. 10). The results are presented in Fig. 3 together with the overlap correction. In one case $\left(\right.$ marked ${ }^{*}$ ) where heat effect D was very much reduced (i.e. $\mathrm{S}^{\prime}$ formation was nearing completion) the overlap correction as described above was judged to be invalid, and the overlap was approximated as the total heat content of effect $\mathrm{D}$. As heat effect $\mathrm{E}$ is largely unaffected by ageing at $170^{\circ} \mathrm{C}$, and as the freshly quenched alloys do not contain any $\mathrm{S}^{\prime}$ (see Ref. 10), the amount of $\mathrm{S}^{\prime}$ precipitated during ageing is thought to be proportional to the change in $\Delta \mathrm{Q}_{\mathrm{S}^{\prime}}$.

To obtain the amounts of GPB zones, $\delta^{\prime}$ phase and $\mathrm{S}^{\prime}$ phase using the $\Delta \mathrm{Q}$ values as presented in Fig. 3, values for the enthalpies of formation, $\Delta \mathrm{H}$, of these zones/phases are needed. Three methods for obtaining $\Delta \mathrm{H}$ values are assessed in this work. 

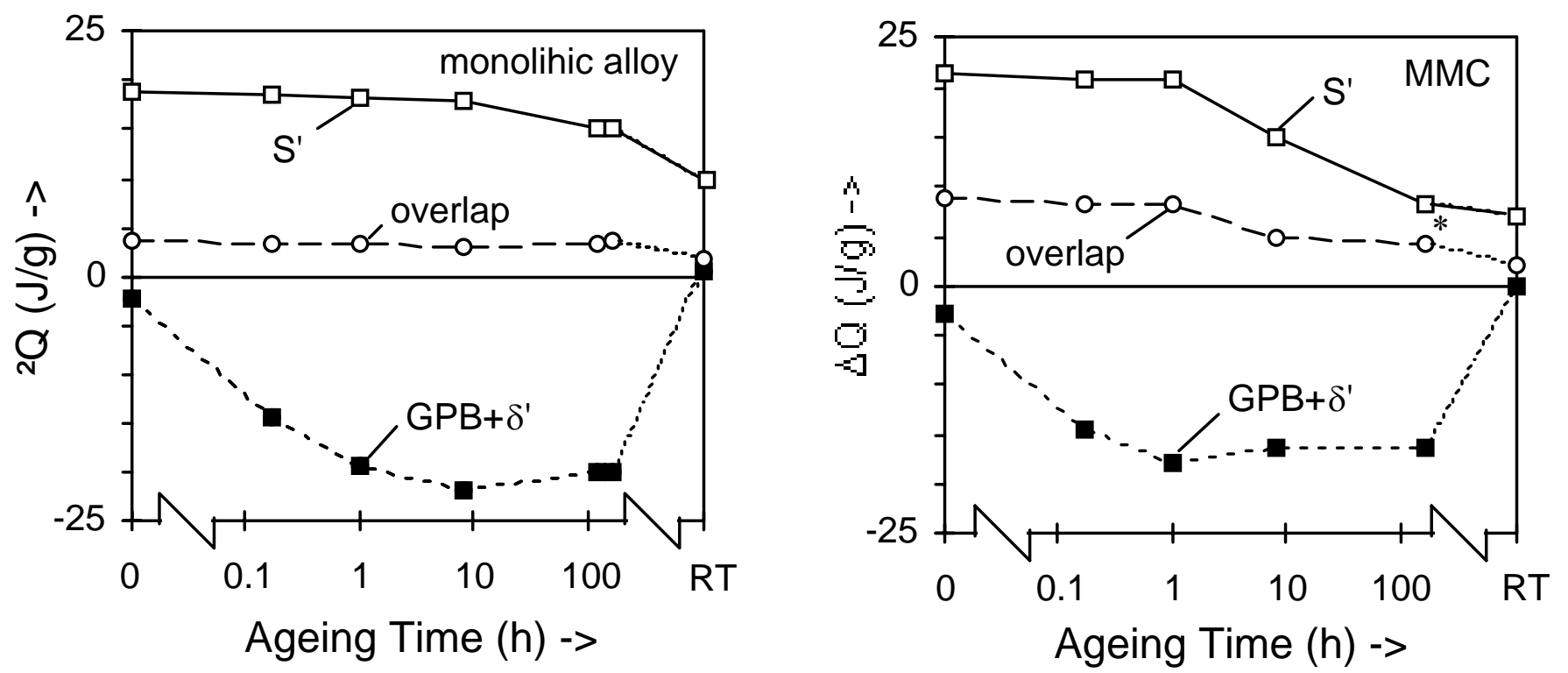

Fig. 3 a,b: Heat contents of the combined GPB-zone/ $\delta^{\prime}$ phase precipitation/ dissolution effect $(n)$ and the $S^{\prime}$ phase precipitation effect ( $\square$ ) corrected for overlap for the 8090 monolithic alloy and the 8090 MMC. RT = reversion treated.

One method relies on the expression for the solid solubility of element A (in atomic fraction), $\mathrm{c}_{\mathrm{A}}$, as obtained from a regular solution model (see Ref. 2):

$$
\mathrm{c}_{\mathrm{A}}=\mathrm{c}_{\mathrm{O}} \exp \left[\Delta \mathrm{H} / \mathrm{k}_{\mathrm{B}} \mathrm{T}\right]
$$

where $c_{O}$ is a constant. By fitting solid solubility data for a certain phase with this expression, a value for $\Delta H$ can be obtained. A similar equation can be derived for phases containing two elements, $A$ and $B$ which form a compound $M_{m} A_{a} B_{b}$ ( $M$ represents the main constituent of the alloy):

$$
\left(\mathrm{c}_{\mathrm{A}}\right)^{\mathrm{a}}\left(\mathrm{c}_{\mathrm{B}}\right)^{\mathrm{b}}=\mathrm{c}_{1} \exp \left[\Delta \mathrm{H} / \mathrm{k}_{\mathrm{B}} \mathrm{T}\right]
$$

In this case $\Delta \mathrm{H}$ represents the enthalpy of formation of one 'molecule' of $\mathrm{M}_{\mathrm{m}} \mathrm{A}_{\mathrm{a}} \mathrm{B}_{\mathrm{b}}$.

A second method for obtaining $\Delta \mathrm{H}$ values relies on precipitation effects observed in DSC curves. It can be shown that the end of a precipitation effect should occur when the composition of the matrix around the precipitate reaches (metastable) equilibrium (1,3). If the metastable solvus of a certain precipitate is known, $\Delta \mathrm{H}$ can be obtained from:

$$
\Delta \mathrm{Q}=\Delta \mathrm{H}\left(\mathrm{x}_{\mathrm{OA}}-\mathrm{c}_{\mathrm{A}}\right)
$$

where $\mathrm{x}_{\mathrm{OA}}$ is the initial concentration of element A dissolved in the Al-rich phase.

When no data on the (metastable) solvus is available, a third method can be used to obtain a $\Delta \mathrm{H}$ value from DSC precipitation effects. In this case data from precipitation effects at different heating rates are necessary and this data is then fitted using Eqs. 2 and 3. For example, for the relatively simple case of a quasi binary alloy (i.e. $x_{O A}=x_{O B}$ ) and $a=b$ it is obtained:

$$
\Delta \mathrm{Q}=\Delta \mathrm{H}\left(\mathrm{x}_{\mathrm{OA}}-\mathrm{c}_{\mathrm{A}}\right)=\Delta \mathrm{H}\left(\mathrm{x}_{\mathrm{OA}}-\mathrm{c}_{2} \exp \left[\Delta \mathrm{H} / 2 \mathrm{k}_{\mathrm{B}} \mathrm{T}_{\mathrm{e}}\right]\right)
$$

The latter method was applied to obtain the enthalpy of formation of GPB zones using effect A in the monolithic alloy (Fig. 1) and the enthalpy of formation of $\mathrm{S}^{\prime}$ phase using effect $\mathrm{D}$ in the monolithic alloy and the MMC (Figs. 1 and 2 ). This results in $\Delta \mathrm{H}_{\mathrm{S}^{\prime}}=0.18$ $\mathrm{J}$ per $\mathrm{g} \mathrm{Cu}$ in $\mathrm{S}^{\prime}=18.0 \mathrm{~J} / \mathrm{g}\left(\mathrm{wt}^{2} \% \mathrm{Cu}\right)^{-1}$ and $\Delta \mathrm{H}_{\mathrm{GPB}}=13.5 \mathrm{~J} / \mathrm{g}(\mathrm{wt} \% \mathrm{Cu})^{-1}$. The graphs resulting from the fitting procedure are presented in Fig. 4. (Note that due to their slightly different $\mathrm{Cu}$ and $\mathrm{Mg}$ contents the fitted curves for the $\mathrm{S}^{\prime}$ precipitation effects are different for the MMC and the monolithic alloy.) Applying Eq. 2 on solid solubility data of the ternary Al-Cu-Mg alloys yields a value of $12 \mathrm{~J} / \mathrm{g}(\mathrm{wt} \% \mathrm{Cu})^{-1}$ for $\Delta \mathrm{H}_{\mathrm{S}^{\prime}}$. (Using Eq. 3, DSC work on ternary Al-Cu-Mg alloys by Jena et al. (13) and by Zahra et al. (15) yield a similar value for $\Delta \mathrm{H}_{\mathrm{S}^{\prime}}$.) The increased $\Delta \mathrm{H}_{\mathrm{S}^{\prime}}$ for the quaternary alloy is consistent with the reduction of the $\mathrm{Cu}$ and $\mathrm{Mg}$ solubility by the addition of $\mathrm{Li}$ (see Eq. 2). Two possible reasons for the increase in $\Delta \mathrm{H}_{\mathrm{S}^{\prime}}$ with the addition of Li to Al-Cu-Mg can be envisaged. Firstly, Li might be incorporated in $\mathrm{S}^{\prime}$, thus lowering the free energy of the $\mathrm{S}^{\prime}$ phase. However, no evidence for this is available and more research would be needed to check this possibility. Secondly, the increased $\Delta \mathrm{H}_{\mathrm{S}^{\prime}}$ for the quaternary alloy could be due to an interaction of $\mathrm{Li}$ atoms in the Al-rich phase with either $\mathrm{Cu}$ or $\mathrm{Mg}$ atoms in the Al-rich phase, which would increase the free energy of the Al-rich phase. The strong reduction of Mg solubility in the Al-rich phase when Li is added to the Al-Mg alloy (21) suggests that such an interaction between $\mathrm{Mg}$ and $\mathrm{Li}$ atoms indeed occurs. Using Eq. 3, DSC work on ternary $\mathrm{Al}-\mathrm{Cu}-\mathrm{Mg}$ alloys by Jena et al. (13) indicate a value of about $6 \mathrm{~J} / \mathrm{g}(\mathrm{wt} \% \mathrm{Cu})^{-1}$ for $\Delta \mathrm{H}_{\mathrm{GPB}}$. Again, the increased $\Delta \mathrm{H}_{\mathrm{GPB}}$ in $8090 \mathrm{may}$ be due to incorporation of some $\mathrm{Li}$ in GPB zones or to an interaction of $\mathrm{Li}$ atoms with $\mathrm{Cu}$ or $\mathrm{Mg}$ atoms, increasing the free energy of the $\mathrm{Al}$ rich phase, but no direct evidence for either is available. 
As the metastable solubility of Li does not correspond with the regular solid solution model, $\Delta \mathrm{H}$ was estimated using the second method described above. For this effect B in the MMC corrected for overlap with the small effect that occurs up to about $110^{\circ} \mathrm{C}$ (at $10^{\circ} \mathrm{C} / \mathrm{min}$ ) was used. The $\delta^{\prime}$ solvus is not influenced by $\mathrm{Cu}$ and $\mathrm{Mg}$ additions (8) and obtained from literature data (see for instance Refs. 22,23). Further it was considered that the solution heat treatment will inevitably cause some Li loss at the surface of the samples. The depth at which the maximum amount of $\delta^{\prime}$ precipitation is halved, $\mathrm{d}_{0.5}$, is estimated from the diffusion coefficient of $\mathrm{Li}$ at the solution treatment temperature $\left(\sim 3.810^{-9} \mathrm{~m} / \mathrm{s}^{2}\right.$, see Ref. 24$)$ and the $\delta^{\prime}$ solvus, yielding $\mathrm{d} 0.5=52 \mu \mathrm{m}$ for ageing at $170^{\circ} \mathrm{C}$. Hence the effective volume in which $\delta^{\prime}$ precipitates form is reduced by about $13 \%$ due to Li depletion. This correction is used throughout the present work. The graphs resulting from the fitting procedure are presented in Fig. 4 and $\Delta \mathrm{H}_{\delta^{\prime}}=20.5 \mathrm{~J} / \mathrm{g}(\mathrm{wt} \% \mathrm{Li})^{-1}$ is obtained. From $\delta^{\prime}$ dissolution effects in published DSC curves of quenched Al-Li alloys $(25,26) \Delta \mathrm{H}_{\delta^{\prime}}$ for monolithic Al-Li is estimated at $\sim 18 \mathrm{~J} / \mathrm{g}(\mathrm{wt} \% \mathrm{Li})^{-1}$.

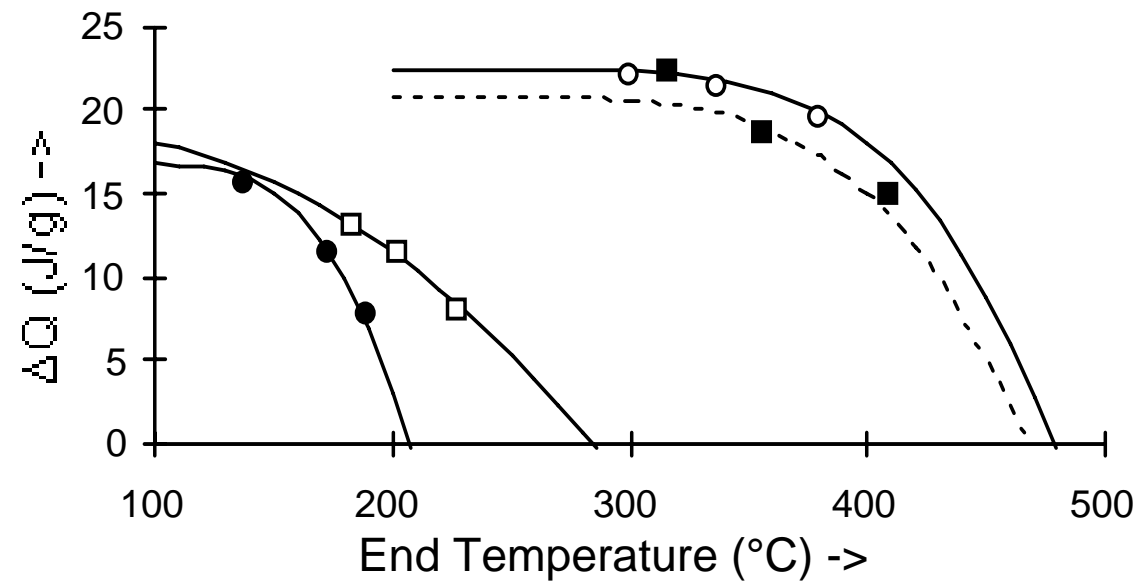

Fig. 4 Total evolved heat $(\Delta \mathrm{Q})$ as a function of the end temperature of the DSC heat effect for GPB- zone formation in the monolithic alloy (I), $\delta^{\prime}$ formation in the MMC $((\square))$ and $\mathrm{S}^{\prime}$ formation in monolithic alloy (o) and MMC (n). The curves represent fits obtained (see text).
To be able to separate the contributions of GPB-zone dissolution and $\delta^{\prime}$ dissolution to $\Delta \mathrm{Q}_{\delta^{\prime} / \mathrm{GPB}}$, the ageing time, $\mathrm{t}$, (at temperature $\mathrm{T}_{\mathrm{i}}$ ) required to reach the same state of the reaction as obtained by heating at a constant rate $\Phi$ to temperature $T_{n}$, is obtained from (see Ref. 10):

$$
\mathrm{t} \cong \frac{\mathrm{T}_{\mathrm{n}}^{2}}{\Phi} \frac{\mathrm{k}_{\mathrm{B}}}{\mathrm{E}} \frac{\mathrm{k}\left(\mathrm{T}_{\mathrm{n}}\right)}{\mathrm{k}\left(\mathrm{T}_{\mathrm{i}}\right)}
$$

where $\mathrm{E}$ is the activation energy of the reaction, $\mathrm{k}_{\mathrm{B}}$ is Boltzmann's constant and $\mathrm{k}(\mathrm{T})$ $=\exp \left(-\mathrm{E} / \mathrm{k}_{\mathrm{B}} \mathrm{T}\right)$. Application of Eq. 5 to the GPB-zone formation effect in monolithic 8090 (Fig. 1) and the $\delta^{\prime}$ formation effect in the 8090 MMC (Fig. 2) indicates that: i) for monolithic 8090 GPB-zone formation is completed within $\sim 2.5 \mathrm{~min}$ at $170^{\circ} \mathrm{C}$, and ii) for the $8090 \mathrm{MMC} \delta^{\prime}$ formation is

completed within $\sim 10 \mathrm{~min}$ at $170^{\circ} \mathrm{C}$. Using these two observations in conjunction with the $\Delta \mathrm{H}$ values and the correction procedures described above, whilst further assuming that the maximum amount of $\delta^{\prime}$ formed is given by the metastable solvus of $\delta^{\prime}$ (1.6wt\% at $170^{\circ} \mathrm{C}$, see Refs. 8,22,23), the amounts of zones/phases formed can now be calculated from the data in Fig. 3 . The results are shown in Fig. 5.
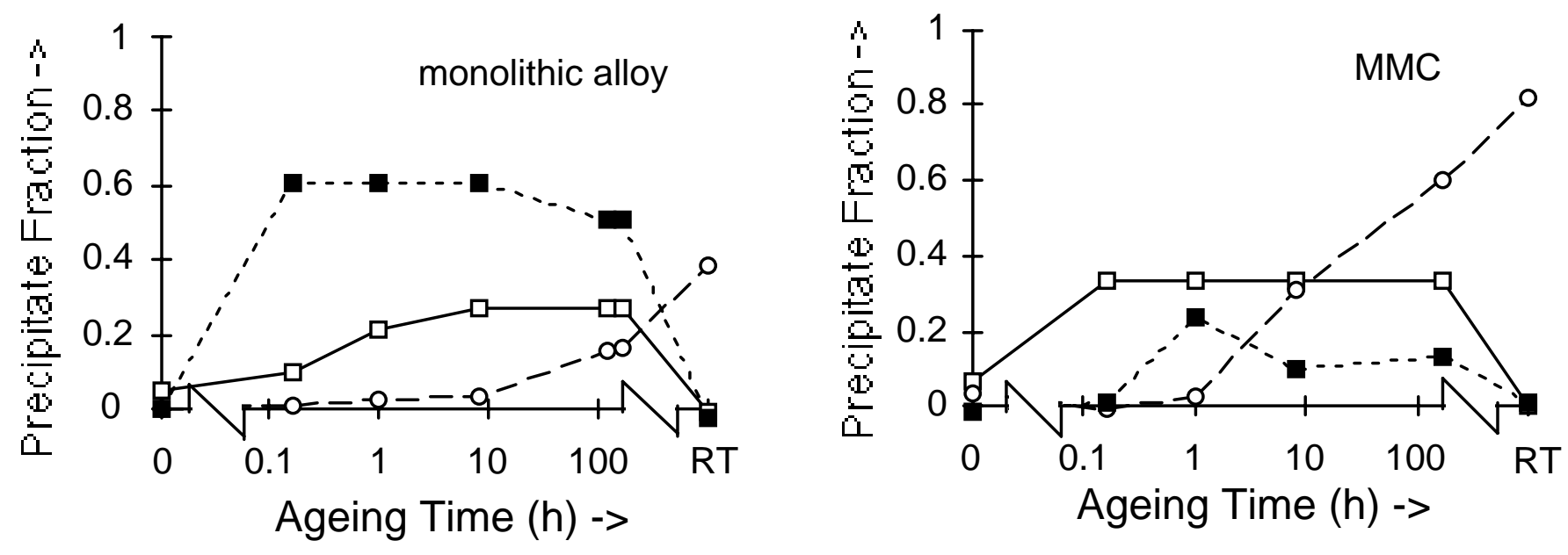

Fig. 5 a,b: Amounts of GPB zones (n), $\delta^{\prime}(\square)$ and $S^{\prime}$ (o) phase in the 8090 monolithic alloy and the 8090 MMC expressed as a fraction of the gross contents of the main constituent $(\mathrm{Li}$ or $\mathrm{Cu})$ present in the zones/phases. $\mathrm{RT}=$ reversion treated.

Fig. 5 shows that very little $\mathrm{S}^{\prime}$ is formed in the monolithic alloy, whilst $\mathrm{SiC}$ addition greatly enhances $\mathrm{S}^{\prime}$ formation. This has been noted in other publications (see e.g. 5,10,14) and hence corroborates the assumptions made in the present work. Further support of these assumptions is obtained from the following observations: i) the sum of the copper fractions incorporated in GPB zone and $\mathrm{S}^{\prime}$ phase is always between 0 and 1 , and ii) a reversion treatment at $286^{\circ} \mathrm{C}$ (above the solvi of GPB zones and $\delta^{\prime}$ ) reduces the GPB zone and $\delta^{\prime}$ phase content to zero. Further, Eq. 5 indicates that the temperature range of the small $\delta^{\prime}$ formation effect in DSC run at $2{ }^{\circ} \mathrm{C} / \mathrm{min}$ for the monolithic 8090 alloy should correspond to a time range of $\sim 10$ to 60 min for isothermal ageing at $170^{\circ} \mathrm{C}$. This is indeed observed (Fig. 5a). 
Apart from observations corroborating other work on monolithic 8090 alloys and 8090 MMCs a number of new observations concerning the thermodynamics and the precipitation kinetics in these alloys can be made. Firstly, Fig. 5 shows that $\mathrm{S}^{\prime}$ phase forms at the expense of GPB-zones and that significant amounts of GPB zones are formed in the monolithic alloy, whilst the addition of SiC particles inhibits their formation. Fig. 4 in conjunction with Eq. 2 defines the metastable solvus of GPB zones and of $\mathrm{S}^{\prime}$. The maximum amount of GPB zones formed in the monolithic alloy during ageing at $170^{\circ} \mathrm{C}(\sim 60 \%$ of the copper is incorporated in GPB, see Fig. 5a) corresponds closely to the metastable solvus in Fig. 4, whilst their stability limit $\left(205^{\circ} \mathrm{C}\right)$ corresponds with a maximum in the endothermic heat flow in the DSC curve at heating rate $2^{\circ} \mathrm{C} / \mathrm{min}$ of the quenched monolithic alloy (Fig. 1). These observations support the metastable solvus of GPB zones as given in Fig. 4. Also the stability limit of S' phase as obtained from Fig. $4\left(\sim 475^{\circ} \mathrm{C}\right)$ is close to a maximum of the endothermic flow in the DSC curves $\left(\sim 485^{\circ} \mathrm{C}\right)$.

\section{Conclusions}

DSC curves of the quenched monolithic 8090 alloy and the $8090 \mathrm{MMC}$ have been used to obtain values for the heats of formation of GPB zones, $\delta^{\prime}$ and $\mathrm{S}^{\prime}$ phase. Using these $\Delta \mathrm{H}$ values and a correction for overlap of effects, the DSC curves of the aged alloys have been interpreted in terms of amounts of precipitates present. The presented interpretations are consistent with previous microstructural investigations. The solvus of GPB zones and of $\mathrm{S}^{\prime}$ phase in 8090 alloys has been obtained. Significant amounts of GPB zones are formed in the monolithic alloy, whilst the addition of $\mathrm{SiC}$ particles greatly reduces the amount of GPB zones formed.

\section{Acknowledgements}

The financial support of the MOD and the EPSRC is gratefully acknowledged. The authors are grateful to Dr. A. Shakesheff of DRA Farnborough for supplying the alloys.

\section{$\underline{\text { References }}$}

$1 \quad$ M.J. Starink and P. van Mourik, Mater. Sci. and Eng., A156, 183 (1992)

2 M. van Rooyen and E.J. Mittemeijer, Metall. Trans. A, 20A, 1207 (1989)

$3 \quad$ M.J. Starink and P. van Mourik, Metall. Trans. A, 22A, 665 (1991)

4 H.M. Flower and P.J. Gregson, Mater. Sci. Techn., 3, 81 (1987)

5 E. Hunt, P.D. Pitcher and P.J. Gregson, Scr. Metall. Mater., 24, 687 (1990)

6 A. Luo, D.J. Lloyd, A. Gupta and W.V. Youdelis, Acta Metall. Mater., 41, 769 (1993)

7 K. Satya Prasad, A.K. Mukhopadhyay, A.A. Gokhale, D. Banerjee and D.B. Goel, Scr. Metall. Mater., 30, 1299 (1994)

8 P. Gomiero, F. Livet, J.P. Simon and O. Lyon, Proc. of the 6th Al-Li Conf., Garmisch-Partenkirchen, Germany, October 711, 1991, M. Peters and P.-J. Winkler, eds., DGM Informationsgesellschaft, Oberursel, Germany, 69 (1992)

9 A.K. Gupta, Gaunt and M.C. Chaturvedi, Phil. Mag. A, 55, 375 (1987)

10 M.J. Starink and P.J. Gregson, submitted for publication in Mater. Sci. Eng.

11 P. Sainfort and B. Dubost, J Physique, 47, C3, 321 (1986)

12 P.J. Gregson and S.A. Court, Scr. Metall. Mater., 30, 1359 (1994)

13 A.K. Jena, A.K. Gupta and M.C. Chaturvedi, Acta Metall., 37, 885 (1989)

14 A.P. Sannino and H.J. Rack, Proc. 4th International Conf. on Al alloys, 11-16 Sept., 1994, Atlanta, Georgia, USA, T.H. Sanders and E.A. Starke, eds., GIT, Atlanta, Georgia, vol. II, 621 (1994)

15 A.M. Zahra, C.Y. Zahra, W. Lacom and K. Spiradek, Proc. Int. Conf. on Light Metals, Amsterdam, June 20-22, 1990, T. Khan and G. Effenberg, eds., ASM, 633 (1990)

16 J.M. Badia, R. Servent and J.M. Antoranz, ibid, 81

17 E.J. Mittemeijer, Liu Cheng, P.J. van der Schaaf, C.M. Brakman and B.M. Korevaar, Metall. Trans., 19A, 925 (1988)

18 E.J. Mittemeijer, J. Mater. Sci., 27, 3977 (1992)

19 E.J. Mittemeijer and I.A. Wierszyllowski, Z. Metallkde., 82, 419 (1991)

20 S. Miyasato and G. Thomas, Proc. of the 5th Al-Li Conf., Williamsburg, Virginia, USA, March 27-31, 1989, T.H. Sanders and E.A. Starke, eds., MCE Publications, Birmignham, U.K., 633 (1989)

21 H.M. Flower and P.J. Gregson, Mater. Sci. Techn., 3, 81 (1987)

22 D.-R. Liu and D.B. Williams, Scr. Metall., 22, 1361 (1988)

23 P.D. Pitcher, R.J. Stewart and S. Gupta, Scr. Metall et Mater., 26, 511 (1992)

24 M.J. Starink and P.J. Gregson, submitted for publication in J. Mater. Sci. Let.

25 A.K. Mukhopadhyay, C.N.J. Tite, H.M. Flower, P.J. Gregson and F. Sale, J. de Physique, C3, 439 (1987)

26 T. Sato and A. Kamio, Proc. of the 6th Al-Li Conf., Garmisch- Partenkirchen, Germany, October 7-11, 1991, M. Peters and P.-J. Winkler, eds., DGM Informationsgesellschaft, Oberursel, Germany, 57 (1992) 